\title{
Biodiesel a partir do óleo de fritura residual e gordura animal (sebo bovino)
}

\author{
Marcos Henrique Ribeiro de Oliveira* (Graduando em Engenharia de Petróleo e Gás na Universidade \\ Potiguar - UnP);
}

Thales Nosman de Negreiros Belarmino (Graduando em Engenharia de Petróleo e Gás na Universidade Potiguar - UnP);

Aílton Pereira da Costa J únior (Graduando em Engenharia de Petróleo e Gás na Universidade Potiguar- UnP);

J éssica Rayany Rodrigues Silva (Graduando em Engenharia de Petróleo e Gás na Universidade Potiguar- UnP);

J oão Paulo da Costa Evangelista (Doutor em Química, Docente da Universidade Potiguar - UnP)

*Email: marcoshro@unp.edu.br

resumo: O biodiesel é um combustível obtido a partir da transesterificação de óleos vegetais ou gorduras animais. Neste trabalho, o biodiesel foi obtido por meio da transesterificação do óleo de fritura residual (OFR), da gordura animal (sebo bovino) e de suas misturas em diferentes proporções. A reação aconteceu usando um álcool (metanol) na presença de um catalisador básico $(\mathrm{KOH})$ na temperatura de $50^{\circ} \mathrm{C}$ por 60 minutos. O biodiesel foi caracterizado pelo índice de acidez, massa específica a $20^{\circ} \mathrm{C}$, corrosividade ao cobre e viscosidade cinemática. As análises físico-químicas demonstram que biodiesel obtido $100 \%$ do sebo bovino foi o que apresentou melhores resultados em todos os requisitos analisados, o mesmo se enquadra na norma exigida pela ANP (Resolução $n^{\circ} 45,2014$ ), o sebo que seria descartado e perdido apresenta baixo custo quando comparado a outras matérias primas para a obtenção do biodiesel, o óleo de fritura residual por sua vez também apresenta um baixo custo e pode ser utilizado para a produção de sabão e outros produtos derivados da glicerina, que seria previamente descartada. Embora sejam matérias primas de fácil acesso e que seu descarte de maneira incorreta pode gerar vários problemas ao meio ambiente, uma solução viável seria a produção de biodiesel, onde geraria renda e sustentabilidade.

palavras-chave:

Óleo de Fritura Residual; Sebo Bovino; Biodiesel; Biocombustível; Transesterificação.

Espaço reservado para organização do congresso. 


\section{Introdução}

Desde o século XX vem sendo explorados campos de petróleo para a produção de combustiveis, porém seu uso tem gerado guerras e discussões em todo o mundo em busca de energia chegando a ser dominado de "ouro negro". Com um crescimento da população e o aumento no número de automoveis, acarretou numa emissão sem controles de gases como $\mathrm{CO}_{2}$, $\mathrm{SOx}, \mathrm{NOx}$, entre outros causadores do efeito estufa, aumento da temperatura da terra, dentre outros problemas catastrófico (EVANGELISTA, 2011).

O Brasil possui uma grande extensão territorial que lhe permite cultivar as oleaginosas em grandes extensões de terras sem se preocupar com a falta de terra os de matéria prima para suprir o restante do mercado. O Brasil é um grande exportador de oleaginosas possuindo assim todas as ferramentas para conseguir ser uma grande referência em relação aos biocombustíveis (IHA, 2010).

Em um país como o Brasil as oleaginosas utilizadas para produção de biodiesel são de grande importância para a sua economia tanto no âmbito da agricultura familiar como no agronegócio, podendo assim, acarretar na geração de novas rendas para os que praticam a agricultura familiar podendo lhes garantir novas oportunidades, e quando se refere ao agronegócio vai acarretar na estimulação do mercado para alcançar as metas desejadas podendo gerar novas oportunidades para os trabalhadores (IHA, 2010).

Pelo elevado valor das oleaginosas tenta-se desenvolver novos compostos que possibilitem baratear o processo para a obtenção do biodiesel como a utilização do sebo bovino, pois o Brasil é um dos maiores produtores de rebanho bovinos do planeta, e pelo valor do material faz-se rentável a sua utilização em alta escala como complemento das oleaginosas (KRAUSE, 2010).

O biodiesel é um combustível produzido a partir de ácidos como (óleos vegetais, gordura animal ou algas), é produzido a partir da transesterificação ou pela esterificação de óleos vegetais e gorduras animais, utilizando um álcool como o (etanol ou metanol), juntamente com um catalisador homogêneo como o KOH ou POH (SILVA, 2010).

O biodiesel é constituído por ésteres metílicos ou etílicos dependendo do álcool utilizado na sua obtenção. No Brasil por possuir uma grande quantidade de etanol utilizado para a obtenção do biodiesel, apesar de que o álcool metílico consegue ter um melhor desempenho em comparação ao etílico, gerando assim um melhor rendimento do produto desejado. A escolha do catalisador utilização para a sua formação também é de grande importância, pois ele também pode influenciar no rendimento e nas propriedades do biodiesel dependendo da quantidade utilizada no processo de obtenção (SOUZA, 2007).

A utilização de biodiesel faz com que a quantidade de poluentes liberados na atmosfera seja reduzida, pelo fato de que em sua composição não apresenta enxofre, nitrogênio e metais. O biodiesel é um ótimo lubrificante, possui um baixo risco de explosão, pois ele precisa de uma fonte de energia superior a 150 graus Celsius para explodir e em relação à liberação de CO2 as plantas capturam todo o CO2 emitido pela queima do biodiesel e separam o CO2 em Carbono e Oxigênio, neutralizando suas emissões (MARZULLO, 2007).

Na busca por matérias-primas de baixo custo, os óleos e gorduras residuais (OGR), principalmente os oriundos de frituras de alimentos comumente denominados óleos de fritura residuais (OFR), surgem como uma alternativa bastante atrativa (ARAÚJO et al, 2013).

Uma vez que seu custo chega a ser 1,5 a 3 vezes mais barato que óleos vegetais refinados ainda não utilizados (ZHANG e JIANG, 2008; PHAN e PHAN, 2008; ALBERICI, 2012; YAAKOB et al, 2013; CHOE e MIN, 2007).

Os óleos de fritura residuais (OFR) constituem um passivo ambiental, cuja utilização na produção de biodiesel com qualidade adequada é comprometida devido à baixa qualidade da matériaprima (AZEREDO, 2014). 
Apesar da baixa qualidade dessa matéria-prima, a utilização de óleos residuais é promissora na produção de biodiesel, pois reduz problemas de contaminação de mananciais e de entupimento dos sistemas de drenagem de águas, os quais necessitam de excessivos e dispendiosos trabalhos na etapa de limpeza e manutenção dessas tubulações (ALBERICI et al, 2012).

A transesterificação é o processo mais viavel (economicamente) até o momento para a produção desse biocombustível, que pode chegar a subtituir parcialmente os combustiveis derivados do petróleo, gerado a partir de fontes renovaveis e tecnologia mais limpas (EVANGELISTA, 2011).

\section{Objetivo}

Avaliar o biodiesel produzido a partir do óleo de fritura residual (OFR), que seria descartado na maioria das residências e restaurantes e a partir da gordura animal (sebo bovino) e das misturas de 3:1 e 1:3 respectivamente, a fim de obter um biocombustível de menor custo que os obtidos com óleos vegetais puros, além de evidenciar um reaproveitamento consciente do OFR e de fontes abundantes de gordura animal.

\section{Metodologia}

\subsection{Procedimento para obtenção de biodiesel}

Os experimentos foram conduzidos nos Laboratórios de Engenharia de Petróleo e Gás na Universidade Potiguar - Natal, Rio Grande do Norte, no período de vinte e dois de agosto a vinte e quatro de setembro de 2015.

As matérias-primas passaram por um pré-tratamento, constituído pela filtragem do óleo de fritura residual e do sebo bovino por um filtro de papel 103 para que os resíduos fossem contidos, posteriormente, colocados na estufa durante noventa minutos a uma temperatura de $110^{\circ} \mathrm{C}$ para a eliminação de qualquer vestígio de umidade, após este processo ambas as matérias-primas apresentaram condições adequadas para a reação de transesterificação. Com as matérias primas isentas de impurezas iniciou-se a produção de biodiesel.

Segundo ROSA (2007), a transesterificação realiza a separação da glicerina do óleo vegetal ou gordura animal durante o processo em que ocorre a transformação destes materiais em biodiesel. A glicerina, que compõe um determinado percentual da massa do óleo vegetal ou gordura animal, quando removida resulta em um produto mais fino, e de viscosidade reduzida. Observa-se a seguir a representação esquemática da reação.

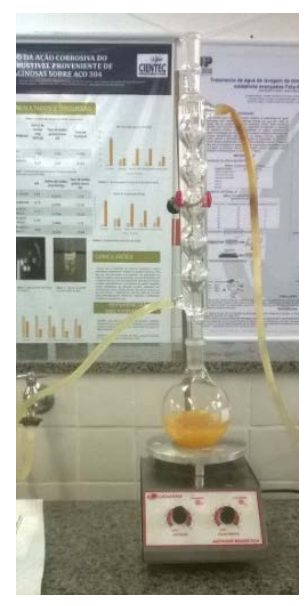

Figura 01: Estrutura da reação de transesterificação, constituído por agitador termomagnético, destilador fracionado e balão de fundo chato. Fonte: Autoria própria.

A figura 1 representa estruturalmente o sistema de transesterificação empregado. A obtenção do Biodiesel consistiu inicialmente em levar 100 gramas de matéria prima a um Becker de $500 \mathrm{ml}$. 
Inicialmente foram escolhidas as quantidades de 100 gramas de OFR e 100 gramas de sebo bovino separadamente. Posteriormente as misturas de: 75-25 (proporção de 3:1 de OFR - sebo bovino), 25-75 (proporção de 1:3 de OFR - sebo bovino) e 50-50 (proporção de 2:2 de OFR - sebo bovino).

A $1^{\text {a }}$ amostra consistiu de 100 gramas de OFR. Os reagentes usados em todas as amostras e nas mesmas condições foram preparados de forma que $35 \mathrm{ml}$ de álcool metílico (metanol) com 1,5 gramas de catalisador básico de hidróxido de potássio $(\mathrm{KOH})$ formando o metóxido de potássio. As 100 gramas de OFR foi misturado ao metóxido de potássio em um balão de fundo chato no agitador magnético durante 60 min. a uma temperatura de $50^{\circ} \mathrm{C}$ para que houvesse a reação da mistura. Após este processo a reação foi posta em um balão volumétrico para que houvesse a decantação da glicerina, e a separação do biodiesel. Este processo ocorreu por 24h. Após 24h foi retirado a glicerina no fundo do balão e feito por 5 vezes a lavagem com água destilada à $70^{\circ} \mathrm{C}$.O biodiesel formado foi levado a estufa por $60 \mathrm{~min}$, eliminando qualquer tipo de umidade restante. O Biodiesel de OFR foi concluído e guardado em recipiente adequado.

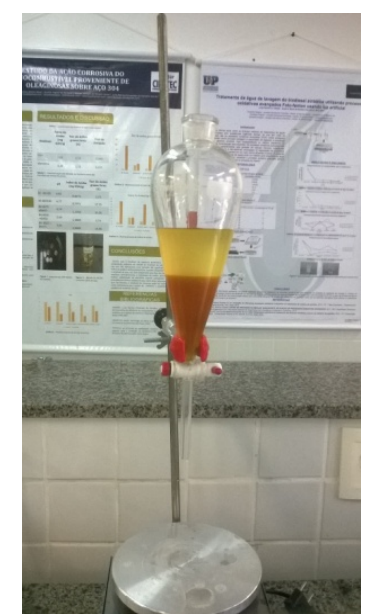

Figura 02: Decantação do Biodiesel realizado no balão volumétrico, Glicerina acumulada pela precipitação Fonte: Autoria própria.

\subsection{Procedimento para lavagem de biodiesel}

Após ás vinte e horas de espera da decantação entre o biodiesel e a glicerina foram separado a glicerina e o biodiesel, para então poder ser realizado o processo de lavagem do biodiesel. Acrescentouse água destilada a $70^{\circ} \mathrm{C}$ no funil juntamente com o biodiesel na razão 2:5 de água para biodiesel, realizada sob agitação para propiciar a retirado de algumas impurezas como catalisadores, álcool etílico, glicerina.

Após o tempo de espera de uma hora da primeira lavagem para que possibilitasse a decantação da água com os contaminantes em relação do biodiesel, foi retirada a água impura e descartada apropriadamente. O procedimento foi realizado mais quatro vezes, com exceção do biodiesel adquirido a partir do sebo bovino puro, que necessitou de oito lavagens. 


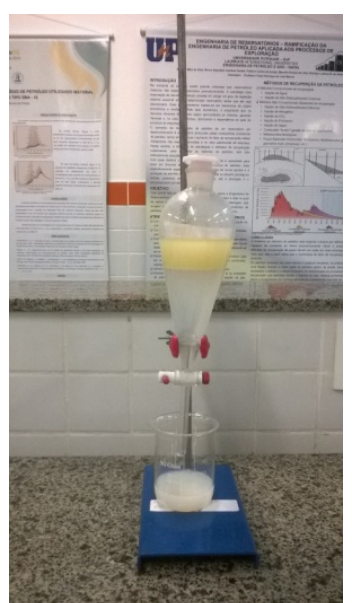

Figura 03: Processo de lavagem do Biodiesel realizado com água destilada à $70^{\circ} \mathrm{C}$. Fonte: Autoria própria.

Após a lavagem p biodiesel foi levado a estufa por uma hora e meia na temperatura de $110^{\circ} \mathrm{C}$, para que as partículas restantes de água presente no biodiesel evaporassem. Em seguida o biodiesel adquirido foi para levado para as análises. Este procedimento de lavagem foi realizado com base em adaptações nas informações dos trabalhos de Evangelista (2011) e Milli (2011).

\subsection{Caracterização dos óleos e biodieseis}

Os óleos e biodieseis obtidos foram caracterizados através de ensaios físico-químicos conforme as normas internacionais da American Society for Testing and Materials (ASTM) contida na resolução $\mathrm{n}^{\circ}$ 45/2014 da ANP. As propriedades físico-químicas utilizadas foram: aspecto, massa específica; viscosidade cinemática; índice de acidez; teor de água e corrosividade ao cobre.

\subsubsection{Aspecto}

Segundo a resolução da ANP n 7 o biodiesel deve apresentar-se límpido e isento de impurezas. Logo, o procedimento adotado consistiu em classificar visualmente cada biodiesel produzido, por sua limpidez e a presença ou não de impurezas.

\subsection{2. Índice de Acidez}

Para determinação do índice de acidez pesou-se aproximadamente 2,5 gramas de cada amostra de biodiesel, adicionou-se $50 \mathrm{ml}$ de uma mistura de éter etílico com álcool etílico (2:1) para solubilizar o biodiesel, acrescentou-se três gotas de fenolftaleína $1 \%$. Em seguida titulou-se a mistura com uma solução de hidróxido de sódio $(\mathrm{NaOH})$ 0,1N previamente padronizada. $\mathrm{O}$ volume gasto de base foi anotado, e calculou-se o índice de acidez conforme a equação a seguir.

Índice de acidez $(\mathrm{mg} \mathrm{KOH} / \mathrm{g})=\frac{\mathrm{V} * \mathrm{~N} * \mathrm{f} * 56,1}{\mathrm{~g}}$

Em que:

$\mathrm{V}$ : Volume de $\mathrm{NaOH}$ gasto na titulação (ml)

$\mathrm{N}$ : Normalidade da solução de $\mathrm{NaOH}$

f: fator de correção da concentração da solução de $\mathrm{NaOH}$

g: massa da amostra de biodiesel em gramas 


\subsubsection{Massa Específica a $20^{\circ} \mathrm{C}$}

Este parâmetro foi analisado por meio da diferença entre a massa da proveta vazia e a massa da proveta com as amostras, assim como a medição do volume nele contido, possibilitando o cálculo da massa específica de cada uma das amostras conforme a equação a seguir.

Em que:

$$
\rho=\frac{\mathrm{m}}{\mathrm{v}}
$$

$$
\begin{aligned}
& \rho \text { : massa específica }\left(\mathrm{Kg} \mathrm{m}^{-3}\right) \\
& \text { M: massa }(\mathrm{Kg}) \\
& \text { V: volume }\left(\mathrm{m}^{3}\right)
\end{aligned}
$$

Para a determinação da massa específica do biodiesel a $20^{\circ} \mathrm{C}$, resfriou-se o combustível em água gelada até que fosse atingida a temperatura da análise. Da mesma forma que na calibração, a massa de biodiesel é determinada pela diferença entre a massa da proveta com o biodiesel e a massa da proveta vazia, determinando assim, a partir da equação citada a massa específica do biodiesel. É de grande importância que para não interferir na pesagem da massa de cada uma das amostras de biodiesel contido na vidraria, a superfície externa da pipeta esteja bem limpa a cada pesagem.

\subsubsection{Corrosividade ao cobre}

O teste de corrosividade ao cobre é um parâmetro estabelecido que determina a capacidade de o combustível causar corrosão em peças metálicas, que podem ser do motor ou do tanque de armazenamento que está associada à presença de ácidos e compostos de enxofre. A necessidade deste parâmetro tem sido discutida, visto que no biodiesel o teor de enxofre é muito baixo. Neste ensaio de corrosividade uma lâmina de cobre previamente polida é submersa no combustível a $60^{\circ} \mathrm{C}$, durante 3 horas. Em seguida, a placa é lavada e comparada com laminas padrões que representam diferentes graus de corrosão, aos quais são atribuídos valores de 1 a 5. Pela norma ASTM o método recomendado é o D130, enquanto que na norma EN 14214 o método é o ISO 2160. Na RANP 07/08, além desses métodos, é estabelecido também o método ABNT NBR 14359. Os valores máximos aceitáveis são grau 1 de corrosão, tanto na norma EN 14214 quanto na RANP 07/08, e grau 3 para a Norma ASTM D6751(FERREIRA,2009).

\subsubsection{Viscosidade Cinemática a $40^{\circ} \mathrm{C}$}

A viscosidade foi obtida através de um viscosímetro capilar Quimis em banho termostático a $40^{\circ} \mathrm{C}$, no qual consiste em medir o tempo necessário para que um volume de líquido flua pelo capilar sob a ação da gravidade e multiplicado este tempo pela constante do viscosímetro. O procedimento consiste em, inicialmente, ligar o equipamento para aquecimento e estabilização da temperatura a $40^{\circ} \mathrm{C}$. Após, coloca-se uma amostra de aproximadamente $60 \mathrm{ml}$ de biodiesel no tubo viscosimétrico, e em seguida faz-se a sucção da amostra até o atingir o menisco, e inverte-se o tubo para retirar o material em excesso. $\mathrm{O}$ tubo com a amostra é imerso no banho termostatizado a $40^{\circ} \mathrm{C}$ preso a uma garra num suporte de modo que o viscosímetro esteja perfeitamente na vertical. Aproximadamente 15 minutos depois, consideramos a temperatura estabilizada, então se retira a pompete para que o líquido comece a fluir. Quando o biodiesel estiver no menisco de referência, inicia-se a cronometragem do tempo até que atinja o outro ponto de referência. Esse tempo é convertido em segundos e aplicado na seguinte fórmula:

$\mathrm{V}=\mathrm{T} * \mathrm{~K}$

Onde:

$\mathrm{T}$ = tempo em segundos;

$\mathrm{K}=$ constante do viscosímetro a $40^{\circ} \mathrm{C}: 0,2158$. 
4. Resultados das análises

\begin{tabular}{|c|c|c|c|c|c|c|c|}
\hline \multicolumn{2}{|c|}{ PROPRIEDADES } & \multicolumn{2}{|l|}{ MÉTODO } & \multicolumn{2}{|l|}{ OFR } & \multicolumn{2}{|c|}{ SEBO } \\
\hline \multicolumn{2}{|c|}{ Aspecto } & \multicolumn{2}{|l|}{ Visual } & \multicolumn{2}{|c|}{ Límpido (LII) } & \multicolumn{2}{|c|}{ Límpido (LII) } \\
\hline \multicolumn{2}{|c|}{$\begin{array}{c}\text { Massa específica à } \\
20^{\circ} \mathrm{C}\left(\mathrm{kg} / \mathrm{m}^{3}\right)\end{array}$} & \multicolumn{2}{|c|}{ ASTM D 4052} & \multicolumn{2}{|c|}{901,19} & \multicolumn{2}{|c|}{894,11} \\
\hline \multicolumn{2}{|l|}{$\begin{array}{c}\text { Cinemática } \\
\left(\mathrm{mm}^{2} / \mathrm{S}^{2}\right)\end{array}$} & \multicolumn{2}{|c|}{ ASTM D 445} & \multicolumn{2}{|l|}{34,3} & \multicolumn{2}{|c|}{29,64} \\
\hline $\begin{array}{r}\text { Índice de acid } \\
\text { (mg KOH/g) }\end{array}$ & & \multicolumn{2}{|c|}{ ASTM D 664} & \multicolumn{2}{|l|}{2,5} & \multicolumn{2}{|c|}{2,4} \\
\hline $\begin{array}{c}\text { Índice de } \\
\text { corrosividade } \\
\text { cobre }\end{array}$ & & \multicolumn{2}{|l|}{ ASTM 130} & \multicolumn{2}{|l|}{$1 \mathrm{~A}$} & \multicolumn{2}{|c|}{$1 \mathrm{~A}$} \\
\hline \multicolumn{8}{|c|}{ Tabela 01: Resultados das matérias primas. } \\
\hline $\begin{array}{l}\text { PROPRIEDADE } \\
\mathrm{S}\end{array}$ & $\begin{array}{l}\text { MÉTOD } \\
\text { O }\end{array}$ & $\begin{array}{l}100 \% \\
\text { OFR }\end{array}$ & $\begin{array}{c}75 \% \\
\text { OFR/ } \\
25 \% \text { SEB } \\
0 \\
\end{array}$ & $\begin{array}{c}50 \% \\
\text { OFR/ } \\
50 \% \\
\text { SEBO }\end{array}$ & $\begin{array}{c}25 \% \\
\text { OFR / } \\
75 \% \\
\text { SEBO } \\
\end{array}$ & $\begin{array}{l}100 \% \\
\text { SEBO }\end{array}$ & $\begin{array}{l}\text { REG. } \\
\text { ANP }\end{array}$ \\
\hline Aspecto & Visual & $\begin{array}{l}\text { Límpid } \\
\text { o (LII) }\end{array}$ & $\begin{array}{l}\text { Límpido } \\
\text { (LII) }\end{array}$ & $\begin{array}{l}\text { Límpid } \\
\text { o (LII) }\end{array}$ & $\begin{array}{l}\text { Límpid } \\
\text { o (LII) }\end{array}$ & $\begin{array}{l}\text { Límpid } \\
\text { o (LII) }\end{array}$ & $\begin{array}{l}\text { Límpid } \\
\text { o (LII) }\end{array}$ \\
\hline $\begin{array}{c}\text { Massa } \\
\text { específica à } \\
20^{\circ} \mathrm{C}\left(\mathbf{k g} / \mathrm{m}^{3}\right)\end{array}$ & $\begin{array}{l}\text { ASTM } \\
\text { D } 4052\end{array}$ & 862,89 & 864,09 & 866,15 & 854,48 & 851,41 & $850-900$ \\
\hline $\begin{array}{c}\text { Viscosidade } \\
\text { Cinemática } \\
\left(\mathrm{mm}^{2} / \mathrm{S}^{2}\right)\end{array}$ & $\begin{array}{l}\text { ASTM } \\
\text { D } 445\end{array}$ & 5,1792 & 5,8266 & 6,474 & 7,553 & 7,9846 & $3,0-6,0$ \\
\hline $\begin{array}{c}\text { Índice de } \\
\text { acidez (mg } \\
\text { KOH/g) }\end{array}$ & $\begin{array}{c}\text { ASTM } \\
\text { D } 664\end{array}$ & 0,71 & 0,8 & 0,44 & 0,89 & 0,43 & $<0,5$ \\
\hline $\begin{array}{c}\text { Índice de } \\
\text { corrosividade } \\
\text { ao cobre }\end{array}$ & $\begin{array}{c}\text { ASTM } \\
130\end{array}$ & 1B & $1 \mathrm{~A}$ & $1 \mathrm{~A}$ & $1 \mathrm{~A}$ & $1 \mathrm{~A}$ & - \\
\hline
\end{tabular}

Tabela 02: Resultado das amostras de biodieseis.

\subsection{Resultados e Discussões}

Por existir um constante conflito da indústria do biodiesel em relação à oleaginosa como a soja, em função do setor alimentício, por este fator busca-se novas fontes de auxílio ou substituição parcial para geração de biodiesel sem aumentar o seu custo, neste trabalho foi realizado estudos da geração de biodiesel com óleo de fritura e sebo bovino cujo uma possibilidade de obtenção para o óleo de fritura poderia ser por meio de arrecadação, ambos possuem um custo relativamente baixo e não influenciam o setor alimentício, sendo assim uma excelente matéria prima para ser utilizada. Foi estudado o comportamento do biodiesel geral pela mistura do óleo de fritura e o sebo bovino em diferentes proporções para analisar os diferentes resultados gerados, assim, podendo analisar as amostras que iriam apresentar as características mais desejadas de acordo com as normas da ANP (Resolução nº45, 2014).

Os resultados obtidos dos compostos no final das análises demonstraram deferentes resultados dependendo das proporções utilizadas em cada amostra, sendo necessário analisar os dados almejados para escolha da amostra que poderá desejar produzir no futuro pelas características demonstradas, como por uma mistura de um biodiesel produzido cuja uma das propriedades esteja a desejar e faça uma mistura entre biodieseis cujo valor agregado deste segundo seja rentável para este processo. 


\subsection{Massa específica}

A massa especifica é a relação entre a massa e o volume do fluido, com as análises podemos observar que o óleo de fritura residual apresenta uma menor densidade visto que o biodiesel feito OFR 100\% puro apresentou uma massa especifica menor que o biodiesel produzido a partir do óleo feito $100 \%$ com sebo bovino, apesar disso o $50 \% / 50 \%$ foi o que apresentou a menor massa especifica como foi mostrado na tabela e no gráfico a seguir. Comparando a tabela 02 com a tabela 03, observou-se uma diminuição da massa específica do sebo em $28,05 \mathrm{Kg} / \mathrm{m}^{3}$ e uma diminuição de $12,3 \mathrm{Kg} / \mathrm{m}^{3}$ do OFR após o processo de transesterificação.

\subsection{Viscosidade Cinemática a $40^{\circ} \mathrm{C}$}

Viscosidade cinemática é a razão entre viscosidade absoluta e a massa específica do fluido, ambas na mesma temperatura. O viscosímetro capilar é um instrumento que possui diversos tipos e modelos destinados a medir a viscosidade de fluidos. Neste estudo foi utilizado o viscosímetro Quimis, utilizado para medir a viscosidade de fluidos. A portaria ANP que especifica o parâmetro de viscosidade de óleo diesel informa que a viscosidade cinemática deve ser analisada a $40^{\circ} \mathrm{C}$, e deve se situar na faixa compreendida entre $2,5 \mathrm{~mm}^{2} / \mathrm{s}$ e $5,5 \mathrm{~mm}^{2} / \mathrm{s}$. Com relação ao biodiesel, este deve ser comercializado com viscosidade cinemática, à temperatura de $40^{\circ} \mathrm{C}$, e deve se situar na faixa compreendida entre $3,0 \mathrm{~mm}^{2} / \mathrm{s}$ e $6,0 \mathrm{~mm}^{2} / \mathrm{s}$, devendo ser límpidos e isentos de impurezas. As amostras que apresentaram viscosidade cinemática estabelecida pelos parâmetros da ANP foram o 100\% OFR e o 75\%OFR/25\%SEBO.

\section{4. Í ndice de corrosividade ao cobre}

A análise do índice de corrosividade ao cobre tomou como referência a Escala padrão- ASTM 130. Onde o cobre polido foi submerso em uma porção de $20 \mathrm{ml}$ de biodiesel nas proporções $100 \%$, $75 \% / 25 \%, 50 \% / 50 \%, 25 \% / 75 \%$ e $100 \%$ óleo de fritura e o de sebo bovino respectivamente.

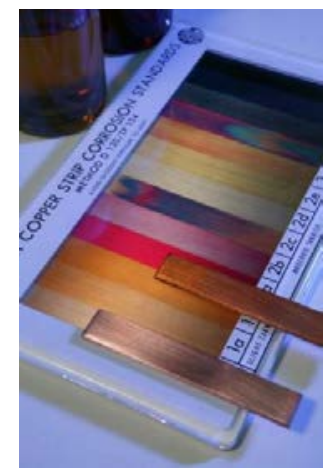

Figura 04: Tabela de cor para definir a corrosividade ao cobre das amostras (ASTM D130).

\section{Conclusão}

Após as análises podemos observar que alguns biodieseis que tiveram como matéria prima o sebo bovino e o óleo de fritura residual se enquadram dentro das especificações exigidas pela norma vigente da ANP (Resolução n ${ }^{\circ} 45$, 2014). Quando o parâmetro analisado foi o índice de acidez o biodiesel $50 \%$ OFR / 50\% SEBO e o $100 \%$ SEBO foram os que indicaram acidez menor que $0,50 \%$, quanto a massa específica o regulamento descreve que a mesma esteja entre $850 \mathrm{~kg} / \mathrm{m}^{3}$ e $900 \mathrm{~kg} / \mathrm{m}^{3}$, os biodieseis que estavam dentro dos limites exigidos foram o 25\% OFR / 75\% SEBO, 75\%OFR / 25\%SEBO e o 
100\% SEBO, quanto a sua viscosidade cinemática os parâmetros são de 3 a $6 \mathrm{~mm}^{2} / \mathrm{s}$. Onde as amostras que apresentarão a viscosidade cinemática estabelecida pelos parâmetros da ANP foram o 100\%OFR e o $75 \%$ OFR/25\%SEBO. Portanto os biodieseis obtidos a partir de $100 \%$ do sebo bovino e $75 \%$ óleo de fritura, foram os que apresentaram melhores nos requisitos analisados, o mesmo se enquadra na norma exigida pela ANP (Resolução $n^{\circ} 45,2014$ ), o sebo que seria descartado e perdido apresenta baixo custo quando comparado a outras matérias primas para a obtenção do biodiesel, o óleo de fritura residual por sua vez também apresenta um baixo custo e pode ser utilizado para a produção de sabão e outros produtos derivados da glicerina, que seria previamente descartada. Embora sejam matérias primas de fácil acesso e que seu descarte de maneira incorreta pode gerar vários problemas ao meio ambiente, uma solução viável seria a produção de biodiesel, onde geraria renda e sustentabilidade.

\section{Biodiesel from frying oil residual and animal fat (tallow beef).}

Abstract: Biodiesel is a fuel obtained from the transesterification of vegetable oils or animal fats. In this work, the biodiesel was obtained by transesterification of frying oil residual, animal fat (tallow beef) and their mixtures in different proportions. The reaction was done using an alcohol (methanol) in the presence of a basic catalyst $(\mathrm{KOH})$ at the temperature of $50^{\circ} \mathrm{C}$ for 60 minutes. The biodiesel was characterized by the index of acidity, specific mass at $20^{\circ} \mathrm{C}$, corrosive to copper and kinematic viscosity. The physical and chemical analyzes show that biodiesel obtained $100 \%$ of beef tallow was what showed the best results in all the analyzed requirements , the same fits in standard required by ANP (Resolution no. 45, 2014). The tallow that would otherwise be discarded and lost presents a low cost when compared to other raw materials for the production of biodiesel, the frying oil residual by its time also offers a low cost and can be used for the production of soap and other products derived from glycerin, which would previously discarded. Although raw materials for easy access and that your discard improperly can generate several problems to the environment, a viable solution would be the production of biodiesel, which would generate income and sustainability.

Keywords: Frying Oil Residual; Bovine Tallow; Biodiesel; Biofuel; Transesterification.

\section{Referências bibliográficas}

EVANGELISTA, João Paulo da Costa. Obtenção de biodiesel através da transesterificação do óleo de arroz utilizando KI / Al 203. 2011. 135 f. Dissertação (Mestrado) - Curso de Química, Centro de Ciências Exatas e da Terra, Universidade Federal do Rio Grande do Norte, Natal, 2011.

IHA, Osvaldo Kojiro. Produção e analise de bio-óleo utilizando oleaginosas que possam contribuir para o aumento da matriz energética renovável Brasileira. 2010. 65 f. Dissertação (Mestrado em Química) - Curso de Química, Universidade de Brasília, Brasília, 2010.

KRAUSE, L. C. Desenvolvimento do processo de produção de biodiesel de origem animal. Tese de doutorado. Porto Alegre, 2008.

SILVA, Nívea de Lima da. Produção de biodiesel: Processo e caracterizações. 2010. 201 f. Tese (Doutorado) - Curso de Engenharia Química, Universidade Estadual de Campinas, São Paulo, 2010.

SOUZA, Rodrigues Hugo de. Obtenção de ésteres etílicos e metílicos, por reações de transesterificação, a partir do óleo da palmeira Latino Americana macaúba - Acrocomia aculeata. 2007. 236 f. Dissertação (Mestrado em Química) - Curso de Química, Faculdade de Filosofia, Ciências e Letras de Ribeirão Preto, São Paulo, 2007. 
MARZULLO, Rita de Cassia Monteiro. Análise de eco eficiência dos óleos vegetais oriundos da soja e palma, visando a produção de biodiesel. 2007. 303 f. Dissertação (Mestrado em Engenharia Química) - Curso de Engenharia Química, Usp, São Paulo, 2007.

ARAÚJ O, C. D. M. de; ANDRADE, C. C. de; SILVA, E. de S.; DUPAS, F. A. Biodiesel production from used cooking oil: A Review. Renewable and Sustainable Energy Reviews, v. 27, p. 445-452, 2013.

ZHANG, J.; JIANG, L. Acid-catalyzed esterification of Zanthoxylum bungeanum seed oil with high free fatty acids for biodiesel production. Bioresource Technology, v. 99, p.8995-8998, 2008.

PHAN, A. N.; PHAN, T. M. Biodiesel production from waste cooking oils. Fuel. n.87, 3490-3496, 2008.

ALBERICI, R. M.; de SOUZA, V.; de SÁ, G. F.; MORELLI, S. R.; EBERLIN, M. N.; DARODA, R. J., Used Frying Oil: A Proper Feedstock for Biodiesel Production?, Bioenergy Research, v. 5, p. 10021008, 2012.

YAKKOB, Z.; MOHAMMAD, M., Overview of the production of biodiesel from Waste cooking oil, Renewable and Sustainable Energy Reviews, p. 184-193, 2013.

CHOE, E.; MIN, D.B. Chemistry of Deep-Fat Frying Oils. JOURNAL OF FOOD SCIENCE. v. 72, N 5, 2007.

AZEREDO, Weine Amorim. Otimização da produção de biodiesel metílico a partir de óleos de fritura residuais (OFR). Goiânia, 2014. 166 p. Dissertação (Mestrado em Química) - Programa de Pós-Graduação em Química - PPGQ, Universidade Federal de Goiás, 2014.

ROSA, M. S. Produção de biodiesel a partir de materiais com altos teores de ácidos graxos livres. Rio de J aneiro, 2007.

MILLI, Brunela Bonatto. Produção de biodiesel a partir da mistura de sebo bovino com óleo vegetal. 2011. 26 f. TCC (Graduação) - Curso de Engenharia Química, Instituto Federal Espírito Santo, Espirito Santos, 2011.

FERREI RA, I von Pinheiro Lôbo e Sérgio Luis Costa; CRUZ, Rosenira Serpa da. Biodiesel: Parâmetros de qualidade e métodos analíticos. 2009. 13 f. TCC (Graduação) - Curso de Química, Departamento de Química Analítica, Universidade Federal da Bahia, Salvador, 2009. 